\title{
The Openness to Cultural Understanding by Using Western Films: Development of English Language Learning
}

\author{
Ian Done D. Ramos* \\ *The University of Suwon, Hwaseong City, South Korea \\ profiandone@gmail.com
}

\begin{abstract}
This paper determined students' interests on: 1) film selections, 2) group discussion and exams, and 3) continuous learning using western films. The results indicote that 1) they were likely to be more confident and expressive when stories have easy sequence of events that may help them organize opinions well for effêctive communication; 2) characterization spoke about their present situation and that gave them enough knowledge about future's life; 3) they were likely to be more interested to join discussions and other types of classroom activities because film selections or topics have abundant cultural inputs to make them more logical in reasoning and decision-making; 4) they were likely to be more active due to the native or foreign speakers's teaching techniques, accent, and diction that can better their learning and performance skills; 5) "thinking like a native speaker" technique could help them express their thoughts and feelings spontaneously and freely without entural botindaries; 6) they were more motivated to learn English because grouping br pdiring helped them compare and contrast the amount of their learning with other students' as basî́ for improvement; 7) when a teacher seemed not strict, but rather helpful, they were likely to be more focused on completing any classroom activities; 8nthey were lassertive to participate in discussion and activity because theme, plot chanacterization, and conflict involved in the analysis attracts them to better understand other cultures and their own culture; and 9)they were more attentive when a teacher gave challenging questions. Oxford (2012) believes that "when allowed to learn in their fovorite way, unpressured by learning environment or other factors, students often use strategtes that directly reflect their preferred learning." Consequently, this paper will serve as basis for needs or situational analysis for establishing language teaching inputs to deyelop students' amount of language learning by considering their attitude of openness to cultural understanding between them and their teachers by using western film in a big class size.
\end{abstract}

Keywords: second language acquisition, Confucianism, attitudinal factors, personality felcton the teaching and learning of culture

\section{Introduction}

Great Expectations by Charles Dickens, Pride and Prejudice by Jane Austen, Oliver Twist by Charles Dickens, and Jane Eyre by Charlotte Bronte are the novels made into films. With these four motion materials, university students who are highly interested in English and culture in a South Korean university may seem to perform communicative competence in a literature class where these materials are used to ignite their potentials and even in other conversation-based activities where students have the communicative encounters with foreign professors in person. Interestingly, the influence of culture difference between Western and Korea play a big factor in understanding human's lives that require students to: 1) reflect on the characters, plots, conflict, themes, and other elements of film analysis; 2) develop critical and creative thinking skills; and 3) perform communicative skills in hopes to arrive at the right conclusion or generalization. 
However, in a more than eighty class population (other semesters, more than a hundred), the researcher-professor observed that some Korean students from diverse departments, at some instances, seemed to have struggles on transmitting their ideas, opinions, and emotions into practical situations. Moreover, when they seemed to have lack of substance in the film analysis and presentation skills, they were likely to show disinterest or less motivation to share answers on the literary works.

This concern is worth investigating particularly because a literature class is one of the elective English courses that is designated to study other cultures while developing English communicative and thinking skills. Elective course means that not all students from various departments take up this type of classes. Therefore, there is a need for students to learn English in a context of culture, since Korea is soaring high towards globalization.

\section{Theory and Literature Review with Empirical Studies}

\section{Krashen's Theory of SLA}

Identifying students' strengths and weaknesses in learning process is the best way by looking into the five main hypotheses of Dr. Krashen's. Theory of SLA rSecond Language Acquisition) that explain how students develop their bility to use the language fluently, accurately, and meaningfully.

The Acquisition-Learning Hypothesis. Krashen (20072 explains that "the 'acquired system' or 'acquisition' is the product of a subonscious process very similar to the process children undergo when they acquire their first language". He explains further that "it requires meaningful interaction in the target language natural communication - in which speakers are concentrated not ho form of their utterances, but also in the communicative act. While, the learned system'or 'learning' is the product of formal instruction and it comprises a conscious process which results to conscious knowledge 'about' the language, for example knom edge of grammar rules". In other words, learning is less effective thân acquisition. One who immerses himself in a communicative environment (e.g. literature and film class) will become more fluent and effective in interactive or communicative challenges.

The Monifor Hypothesis It is defined as "a conscious learning that can only be used as a monitor or an editor." In other words, "the acquisition system is the utterance initiator, while the learning system 'performs the role of the 'monitor' or the 'editor"' (Krashen, 2007). Krashen elaborates that 'the 'monitor' acts in a planning, editing, and correcting function when threespecific conditions are met; that is, the second language learner has sufficient time at hís/her disposal, he/she focuses on form or thinks about correctness, and he/she knows the rule". This hypothesis best describes learners (e.g. English majors) who are eager to develop their skills in English classes by assessing or evaluating themselves how far they have learned or acquired the language.

The Natural Order Hypothesis. It refers to "the acquisition of grammatical structures that follows a 'natural order' which is predictable" (Krashen, 2007). That means that structures can be acquired earlier and others come later. Krashen further explains that "this order seemed to be independent of the learners' age, L1 background, conditions of exposure, and although the agreement between individual acquirers was not always 100\% in the studies, there were statistically significant similarities that reinforced the existence of a Natural Order of language acquisition". Learners may acquire language inputs based on the amount of exposures with people, reading materials, meaningful classroom encounters (e.g. film analysis discussion and presentation), daily experiences in communicative environments, etc. In developing a syllabus, Krashen "rejects grammatical sequencing when the goal is language acquisition".

The Input Hypothesis. According to Krashen (2007), humans acquire, not learn, language in the only one way - by understanding messages or by receiving "comprehensible input". He explains further that "the learners improve and progress along 
the 'natural order' when they receive second language 'input' that is one step beyond their current stage of linguistic competence". He shows an example that "if learners are at a stage ' $i$ ', then acquisition takes place when they are exposed to 'Comprehensible Input' that belongs to level ' $i+1$ '. In other words, a teacher or a curriculum developer should anticipate progression of L2 acquisition or learning when designing materials or syllabus, and this should be processed meaningfully in classroom group discussion and other forms of communicative activities (e.g. teacher's input for film analysis discussion and presentation, plus their experiences through practical questions provided).

The Affective Filter Hypothesis. It refers to "a mental block, caused by affective factors that prevent input from reaching the language acquisition device" (Krashen, 2007). Krashen explains further that "learners with high motivation, self-confidence, a good selfimage, and a low level of anxiety are better equipped for success in second language acquisition; low motivation, low self-esteem, and debilitating anxiety can combine to 'raise' the affective filter and form a 'mental block' that prevents comprehensible input from being used for acquisition." In class, when a learner is intimidated or to conscious of many things, he/she may experience inefficiency of languadge acquisition at some point. For Korean learners, this is very obvious due to their classroom orientation in lower years as well as their culture influence.

The researcher believes that activities and interactive materials with careful and strategic instruction are tools to test the amount of students' learnng in which Krashen's five hypotheses are reflected. Facturan's (2013) study experimented Practical English 1 students in a South Korean university As for the findings gathered from the key informants of the control group, the participants of the activities were able to: a) develop motivation on speaking freely with a partner and confidence to be a good discussant in the group, b) improve listening, speaking, and promuncration skills while building relationship with others through effective interview activities, c) develop active participation in the group. As for the key infermants from the experimental group, they were able to: a) develop good participation in a group while building vocabulary and motivation, b) appreciate immersion while realizing their strengths and weaknesses on learning English in different methods, and c) overcoming shyness and awkwardness in communicative activities. Moreover, as the structure design of the activities are culture-oriented, studentcentered, and user friendly, the language experts who participated in the experiment verbalized that they enjoyed the activities and found them easy and useful, thus becoming more excited and eager to present their output. In conclusion, it is very clear that the interactive learning materials and activities were very effective with the help of the teacher's expertise and the students' cooperation, active participation, experiences, and communicative competence. The learning experience has become productive.

With the Krashen's theory, Korean students can still be assessed further on how much learning they have had in the English language implementation and what impact it contubutes to their lives. To deeply understand their learning capacity, their learning attitude and learning styles in the context of Korean culture should also be taken into consideration.

\section{The Learning Attitude and Styles}

Korean students' learning attitude and styles are huge factors in the learning process, especially in the English literature class which deals with Western cultures and their own culture. At some instances, students may seem to be hesitant to show communicative competence due to their classroom orientation when they were in elementary, middle school, and high school classes (or even at the university level) where teachers speak a lot while students just listen passively. This act may be influenced by Confucianism which dwells "much emphasis on the virtue of social hierarchy". Ramos' (2012) and Ynclino's (2013) studies testified that students' passive behavior towards English as a Foreign Language were carried out by previous classroom orientation with a touch of culture, learning attitudes, and learning styles. 
In contrast, Ramos' (2013) recent study seemed to appear that English majors have now made their effort to change their learning styles and strategies towards communicativebased classes. In the focused group discussions (FGDs), students expressed their feelings that they dislike: a) a professor who asks students for presentation without his/her professional inputs, b) book-based teaching-learning type, and c) lecture type. Seoul National University Prof. Kim Seon Kon (2013) emphasized that Korean society is not Confucian anymore. She shows evidence that "Korean students even challenge their teachers at school, and employees often disobey their superiors at work and go on strike".

Young, open-minded learners in Korea have realized the importance of learning English that reshapes their learning attitude and styles. There are two attitudinal factors that relate to these, namely: a) encouraging intake and b) utilizing language heard for acquisition. In encouraging language intake, others have said that "motivational variables... determine whether or not the student avails himself of... informal langlage contexts" (Gardner, Smythe, Clement, and Gliksman, 1976, in Krashen, 2002). Krashen explains that "they are simply factors that encourage acquirers to communicate with speakers of the target language, and thereby obtain the necessary input, or intake, for language acquisition". In utilizing the language heard for acquisition, "pepformers simply heard a second language with understanding that appears to be nedessary but is not sufficient for acquisition to take place" (Krashen 2002). That means that "the acquirer must not only understand the input but must also, in a sense, be 'open' to it'. According to Dulay and Burt (1977), performers with high or strongosocio-affective filters will acquire less of the language directed at them, as less input is "allowed in" to the languageacquisition device.

In Ramos' study (2012) on learning athitude towards communicative activities, the data explain that students never went out (or not attend the class the following day) whenever there was a speaking activity. Some even treated it as a challenging part. In fact, there were some who were excited to practice, as it is useful in job-seeking, and were proud eventually when they had improved or achieved something. Thus, they were motivated to succeed.

Moreover, personality factors are interrelated with motivational factors. In H. D. Brown's view, whe person with high self-esteem is able to reach out beyond himself more freely, to be less inhibited, and because of his ego strength, to make the necessary mistakes involved in language learning with less threat to his ego". On the other hand, "the less self-confiden person may understand the input but not acquire, just as the selfconscious person may filter (or avoid) in other domains" (Krashen, 2002).

In further observation, Ramos $(2012,2013)$ identified the students' positive attitudes as follows: a) they were only participative in communicative activities when they were not conscious of grammar and when they knew they could talk a lot freely about any interesting topics, b) they easily learned when slangs were introduced in the conversation with teachers being open-minded, and c) they easily developed their communicative competence when they traveled abroad and when it is applied in other practical situations, just like meeting foreigners. These manifestations indicate that when the students feel at ease in the classroom due to teacher's personality and effort, they seek out intake by volunteering (he may be a "high input generator") and may be more accepting of the teacher as a source of intake (Seliger, 1977, in Krashen, 2002). Thus, positive attitudes toward the classroom and teachers promote self-confidence and motivation, and that students with such attitudes tend to have more results in acquiring the language.

In the Korean English as a foreign language (EFL) context, Rajabi and Ketabi (2012) emphasized that "the teaching and learning of culture encompasses all aspects of human life: lifestyle, behavior, thoughts and the value system of the target culture." They pointed out that "learners are made aware of the various dimensions of culture as well as the rules of the language." However, they warned that "confusion and conflict can arise among people engaging in cross-cultural interaction because the culture one is born in to is generally taken for granted as reality." McLeod (1980) asserts that it is then important for 
the teacher to understand the values he is transmitting and also the values of the students' cultures."

\section{Results and Discussions}

This section discusses students' interest on the film selections, group discussion and exam, and continuous learning. Through the student questionnaire survey, the teacher interview, and the teacher-reseacher himself (positionality in qualitative research), findings of this study are shown below.

Figure 1 presents the students' interest on the film selections.

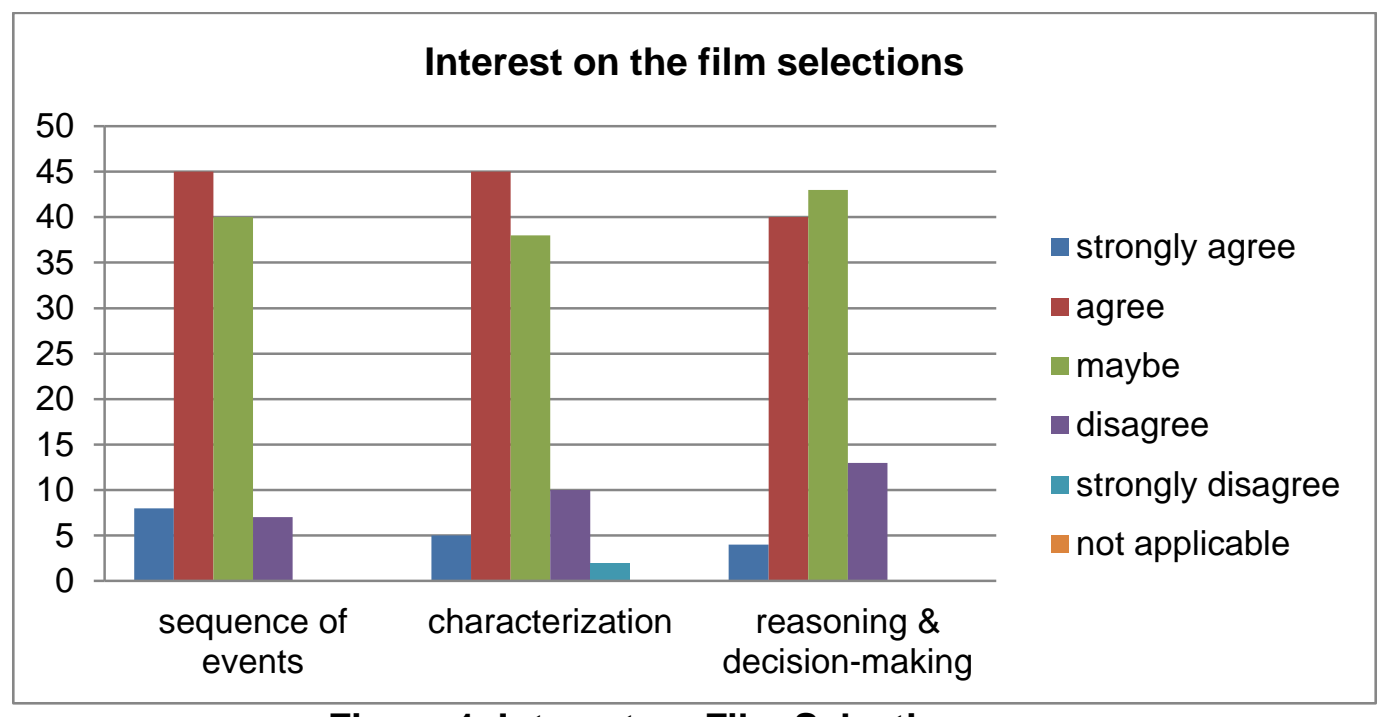

Figure 1. Interest on Film Selections

As for sequence of events, $45 \%$ of the student respondents agreed and $8 \%$ strongly agreed that they were likely to be more confident and expressive when stories have easy sequence of events that may help them organize opinions well for effective communication, but $7 \%$ disagreed. It is surprising to know that $40 \%$ were not sure on this.

As for characterization, $45 \%$ of the student respondents agreed and 5\% strongly agreed that it spoke about their present situation, and that gave them enough knowledge about future's life, but $10 \%$ disagreed and $2 \%$ strongly disagreed on this. The rest $38 \%$ were not sure whether it coule help them in their future.

As for reaśoning and decision-making, $43 \%$ were not sure whether they were likely to be more interested to join discussions and other types of classroom activities. However, $40 \%$ agreed and $4 \%$ strongly agreed that they were more interested because film se ections or topics have abundant cultural inputs to make them more logical in reasoning and decision-making. The rest $13 \%$ disagreed on this.

Film stories reflect human lives. When a person encounters happy, exciting, and challenging episodes on film or TV drama, he or she tends to also have a happy life in reality. Oxford (2012) believes that "when allowed to learn in their favorite way, unpressured by learning environment or other factors, students often use strategies that directly reflect their preferred learning." Learning from sequence of events and characterization may guide students to ponder about their future's endeavor and eventually, they will take action to reach goals. Moreover, in the course of exposing students to English literature films (especially with love and romance, money, social class, and violence themes), students would learn to develop strategic competence in preparation for negotiations in order to survive in a group discussion. Strategic competence refers "the coping strategies that communicators employ to initiate, terminate, maintain, repair, and redirect communication" (Richards and Rodgers, 2008). This kind of undertakings heightens student's organization skills not only in class, but also in daily life encounters. 
Part of any undertaking is the consideration of cultural inputs. Students are aware of cultural inputs to make them more logical in reasoning and decision-making in a given context, that led them to exert their effort on participating in the class activities. Oxford (2002) explains that "students' L2 learning styles and their underlying learning styles are often directly related to culturally inculcated values" (p.127).

Figure 2 presents the students' interest on group discussion and exam.

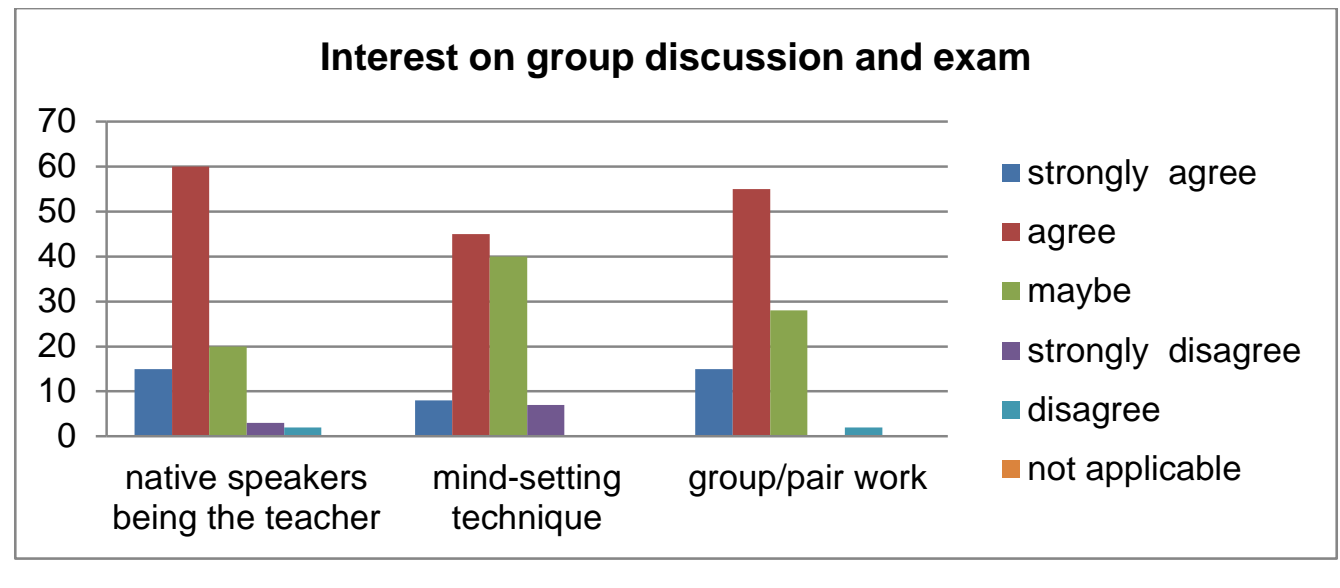

Figure 2. Interest on Group Díscussion and Exams

As for native speakers being the teachers, $60 \%$ of the students respondents agreed and $15 \%$ strongly agreed that they were likely to be more active due to their teaching techniques, accent, and diction that can better their learning and performance skills, but $3 \%$ disagreed and $2 \%$ strongly disagreed. The temaining $20 \%$ were not sure whether they could agree on this.

As for mind-setting technique, $45 \%$ of the student respondents agreed and $8 \%$ strongly agreed that "thinking like a natice speaker" technique could help them express their thoughts and feelings spontaneously and freely without cultural boundaries, but 7\% disagreed on this Moreover, 40\% were not sure on this technique.

As for group or pair work activities, 55\% agreed and $15 \%$ strongly agreed that they were more motivated todearn English because grouping or pairing helped them compare and contrast the amount of their learning with other students' as basis for improvement. However, $2 \%$ strongy disagreed on this, while $28 \%$ were not sure whether they were more motivated.

One indication that students are open to cultural understanding is the amount of immersion with the English native speakers around at their heart's content. When students have a Cesirable outcome from people with good accent and diction, they are likely to develop or heighten (only for some) their performance skills in any communicative encounters. Nunan (2012) emphasizes that "opportunities to reflect on the learning process, and to develop new learning skills could help learners to identify and articulate differences between their ... experiences and those encountered at a university." With students' amount of exposure to native speakers or foreign teachers at the university, students have learned techniques on how to strengthen their communicative abilities. "Thinking like a native speaker" refers to putting aside their L1 attitude and communicative act and utilize L2 metalinguistic components. According to Kajabi and Ketabi (2012), "social and psychological distance extensively influence learners' attitude, whether positive of negative, towards the target language and its culture."

Moreover, group or pair work activity is also a way to practice these components. Earning collective points with groups is a form of learner's technique to survive in a class. Koreans always help each other and care so much about their fellowmen -- that is one of their inculcated values. Oxford (2012) shows results that "a number of the best learners use affective and social strategies to control their emotions, to stay motivated, to 
cooperate, and to get help." For slow learners, they could develop their skills and the spirit of motivation when they feel the comfort zone with their group members; thus, they become more result-oriented in the written exam and other oral activities.

Figure 3 presents the students' interest on continuous learning.

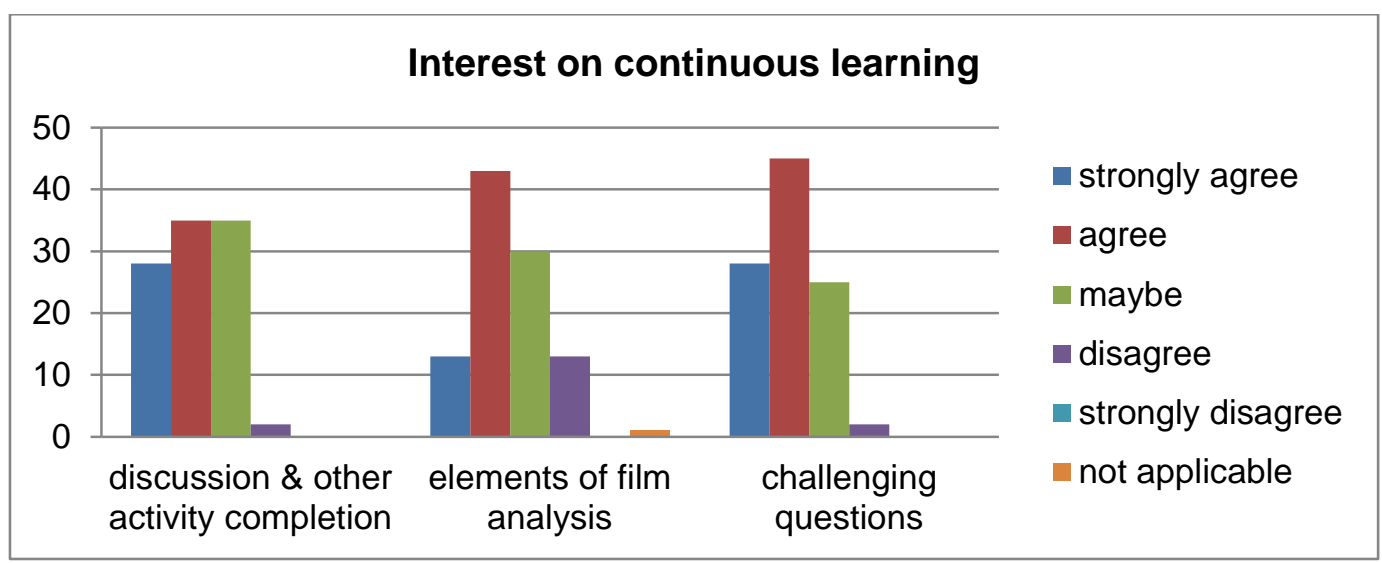

Figure 3. Interest on Continuous Learning

As for discussion and other activity completion, it is interesting to know that $35 \%$ of the student respondents agreed and $28 \%$ strongly agreed that when a teacher seemed not strict, but rather helpful, they were likety to be morefocused to complete any classroom activities; only $2 \%$ disagreed. The rest $35 \%$ were not sure whether teachers were helpful enough.

As for elements of film anatysis, $43 \%$ agreed and $13 \%$ strongly agreed that they were assertive to participate in discussion and activity because theme, plot, characterization, and conflict involved in the analysis attacts them to better understand other cultures and their own culture; whila, $13 \%$ disagreed. In fact, $30 \%$ were doubtful on this and $1 \%$ thought it is not applied or observed in the class.

As for chalkenging question $45 \%$ of the student respondents agreed and $28 \%$ strongly agreed that they yere moreattentive when a teacher gave challenging questions. However, $2 \%$ disagreed while $25 \%$ were not even sure whether challenging questions affected them.

Since Korean society has not treated English as a second language, learning and using the language are considered critical undertakings. With their classroom orientation in lower years, university students seem to have difficulties in communicative challenges. In Ramos' (2013) stúdy, students were exposed to book-based learning, listen-and-repeat, lecture type, writing, and other passive teaching-learning approaches. Consequently, when asked to speak by a strict teacher, students were likely to step backward. However, teacher personality as well as his/her teaching styles shown in this study affected student's good classroom performance. It is understood, therefore, that providing a meaningful language experience is essential. Richards (2012) argues that "activities which seek to develop a reflective approach to teaching aims to develop the skills considering the teaching process thoughtfully, analytically, and objectively as a way to improve classroom practices."

Moreover, as for conversation-based classes, a few foreign teachers tend to ask any questions due to their inculcated values of being open-minded and expressive to possibilities, while some Korean students are not all the time due to their passivity and culture orientation. Therefore, it is also important to take note that asking students challenging (or personal) questions is associated with cultural values. Rajabi and Ketabi (2012) also believes that "teachers need to reflect on their cultural judgment and adjust their world-view in the light of these cultural constraints" if there is any, since "culture cannot be thought separate with its social value" Lyons (1990). To maximize students' 
potentials, localizing cultural values should be taken into consideration so that students' positive assertion on developing their English language skills further can be fully realized.

\section{Conclusion}

In some South Korean universities, it is a fact that a big group of university students are grouped together for an elective English class. A notion that teaching-learning process can be impossible to promote quality outcome may start to ring in an argumentation table, especially when students are perceived to have different education backgrounds, learning styles, culture orientation, and other factors that impede skills development. However, in this study, it is arguable to claim that teaching English as a Foreign Language (EFL) in a multi-level of English proficiency is always hard in a South Korean university. As long as students of a big class size have a common interest in an English culture class fácilitated with interactive materials and group activities by using films and appropriate teaching techniques, teaching and learning can be processed fruitfully as it expected to happen.

As shown in the results, students' interests in the English language learning and culture were dependent on how sequence of events, characterization, reasoning and decisionmaking, mind-setting technique, group or pair wopk discussion and other activity completion, elements of film analysis, and challenging questions were managed in classroom discussions or activities. Moreover, native speakers being the teacher also gave a big factor in achieving students' classroom and personal goals. Most often, their learning styles and attitudes can be refined by how culture and classroom orientations in relation to learning English drive their attention to succeed. Students were likely to be more expressive, confident, and motivated infilm selections, group discussion and exams, and continuous learning due to their bepeflits they could harvest at the end of each day.

While culture is a part of leakning process, students realized the importance of openmindedness to absorb cultural and language inputs that serve as tools to highly involve themselves in the activities. Their attitude or behavior and learning styles were also affected to reach the postive edge of their learning. Rajabi and Ketabi (2012) emphasized that "the teaching and learning of culture encompasses all aspects of human life: lifestyle, behavior, thoughts and the value system of the target culture."

Indeed, professors should consider teaching English as culture-based so as to create a driving force to develop students' potentials for practical purposes. Kim (2002) in the study "Teaching Culture in the English as Foreign Language Classroom" concluded that a) culture should be integrated in the language curriculum in which awareness of teacher's beliefs about culture can be resolved from making stereotypes, and b) critical discussion about culture where students and teachers are actors to diminish culture biases while students developing communicative skills in English. Consequently, these students may be ready to undergo communicative challenges as they have become socially-culturally competent for globalization.

For other educators and students, this paper will then provide basis for a needs and situational analysis, as they reflect on their teaching-learning tools in seeking answers to their own culture-based classroom experience. Moreover, inputs for teaching techniques and choice of materials that suffice students' interests may also be formulated for their respective classes.

\section{Acknowledgement}

This article is a revised and expanded version of a paper entitled, Diminishing Cultural Boundaries in the English Literature and Film Class, presented at the International Symposium on Advanced and Applied Convergence held on November 14-16, 2013 in Seoul, South Korea. This is also supported by the Department of English and Literature of the University of Suwon, Association of Filipino Educators in Korea (AFEK), Ramos' family, Kim Jin Hyuk, Uhm Sunmee, and Kim Joong Woo. 


\section{References}

[1] S. Krashen, "Theory of Second Language Acquisition", 2007, Retrieved August 10, 2011, from http://www.sk.com.br/sk-krash.html.

[2] S. Krashen, "Second Language Acquisition and Second Language Learning", 2002, Retrieved August 10 , 2011, from http://sdkrashen.com/SL_Acquisition_and_Learning/index.html.

[3] N. M. Facturan, "Effectiveness of the Interactive Learning Materials in English 1 in a South Korean University”, Ed.D. Dissertation. University of the Visayas, Cebu City, Philippines, March 2013.

[4] I. D. Ramos, "The English Language Instruction in a South Korean University: Inputs for Teaching English as a Foreign Language (TEFL)", Ed. D. Dissertation, University of the Visayas, Cebu City, Philippines, (2012) May.

[5] I. D. Ramos, "Diminishing Cultural Boundaries in the English Literature and Film Class," J. J. Kang, (Eds.), Advanced and Applied Convergence Letters (AACL), Seoul: The Institute of Internet, Broadcasting and Communication, vol. 01, no. 01, (2013), pp. 159-162.

[6] I. D. Ramos, "English Majors' Expectations, Experiences, and Potentials in the English Communicative Environments: Basis for Curriculum Development Training Program Towards Korea's Globalization," in Proc. 2013 KOTESOL International Conference Proceedings, (2013), October 12-13, p.101.

[7] A. S. Ynclino, English Language Teaching in Korea: Filipino Teachers' Perspectives. Ed.D. Dissertation. University of the Visayas, Cebu City, Philippines, (2013) March. ${ }^{\bullet}$

[8] S. K. Kim, "Korea is no longer a Confucian Society," The Korea HeraldAsia New Network, August 17, 2013, Retrieved September 18, 2013, from www.nationmultimedia.com/opinion.

[9] R. Gardner, P. Smythe, R. Clement, and L. Gliksman, "Second Language Learning: A SocialPsychological Perspective," Canadian Modern Language Reyiew, vol 32, (19)76), pp. 198-213.

[10] H. Dulay and M. Burt, "Remarks on Creativity in Language Acquisition, M. Burt, H. Dulay, and M. Finnochiaro (Eds.), Viewpoints on English as a Second Language, New York: Regents, (1977), pp. 95126.

[11] H. D. Brown, "Affective Variables in Second Language Acquistion”, 2006, Retrieved September 11, 2013, from http://onlinelibrary.wiley.con

[12] H. Seliger, "Does Practice Make Perfect? A Study of Interaction Patterns and L2 Competence," Language Learning, vol. 27, no. 2,(1977), pp. 264-278.

[13] S. Rajabi and S. Ketabi, "Aspects of Cultural Elements in Prominent English Textbooks for EFL Setting," Theory and Practice in Language Studies, 2012 Academy Publisher Manufactured in Finland, vol. 2, no. 4, (2012) April, pp. 705-712.

[14] B. McLeod, "The Relefance of Anthrorology to Language Teaching." K. Croft (Ed.), Readings on English as a Second Nanguage: For teachers and Trainee Teachers, 2nd edition, Boston: Kittle, Brown and Company, pp 89-90, 1980.

[15] R. L. Oxford Language Learning Strategies in a Nutshell: Update and ESL Suggestions," C. J. Richards and W.'A. Renanya (Eds.), Methodology in Language Teaching, New York: Cambridge University Press, (2012), pP. 125-127.

[16] J. C. Richards and T. S. Rodgers, Approaches and Methods in Language Teaching, New York: Cambridge University Press, (2008).

[17] D. Nunan, "Learnen Strategy Training in the Classroom: An Action Research Study," C. J. Richards and W. A. Renanye (Eds.), Methodology in Language Teaching, New York: Cambridge University Press, (2012), p. 143.

[18] J. Lyons, Language and Linguistics, Cambridge: Cambridge UP, (1990).

[19] J. C. Richards, "Theories of Teaching in Language Teaching," C. J. Richards and W. A. Renanya (Eds.), Methodology in Language Teaching, New York: Cambridge University Press, (2012), p. 23.

[201. Kim, "Teaching Culture in the English as Foreign Language Classroom," The KOTESOL Journal. vol. 5, 10. 1, Fall/Winter (2002), pp. 28-40.

\section{Author}

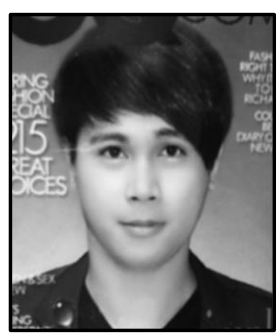

Ian Done D. Ramos, he completed Doctor of Education major in English Language Teaching, Master of Arts in English major in Teaching English to Speakers of Other Languages, Diploma in Special Education major in Learning Disability, and Bachelor of Secondary Education major in English. With the eleven-year teaching experience, he has published a book titled, "Writing in the Discipline," and research articles and has conducted workshops to teachers. Currently, he teaches graduate school and undergraduate courses under the Department of English and Literature at the University of Suwon, South Korea. 
He has a full understanding on how teaching-learning process works to support language needs of individuals. Most of his training foundations taken from Silliman University, the oldest American university in the Philippines, and some Philippine universities have influenced the shape of his professional activities in South Korea and his home country. He is very much interested in Language Curriculum and Materials Development, Language Assessment and Testing, Teaching Methodology, English for Specific Purposes (ESP), and Educational Research.

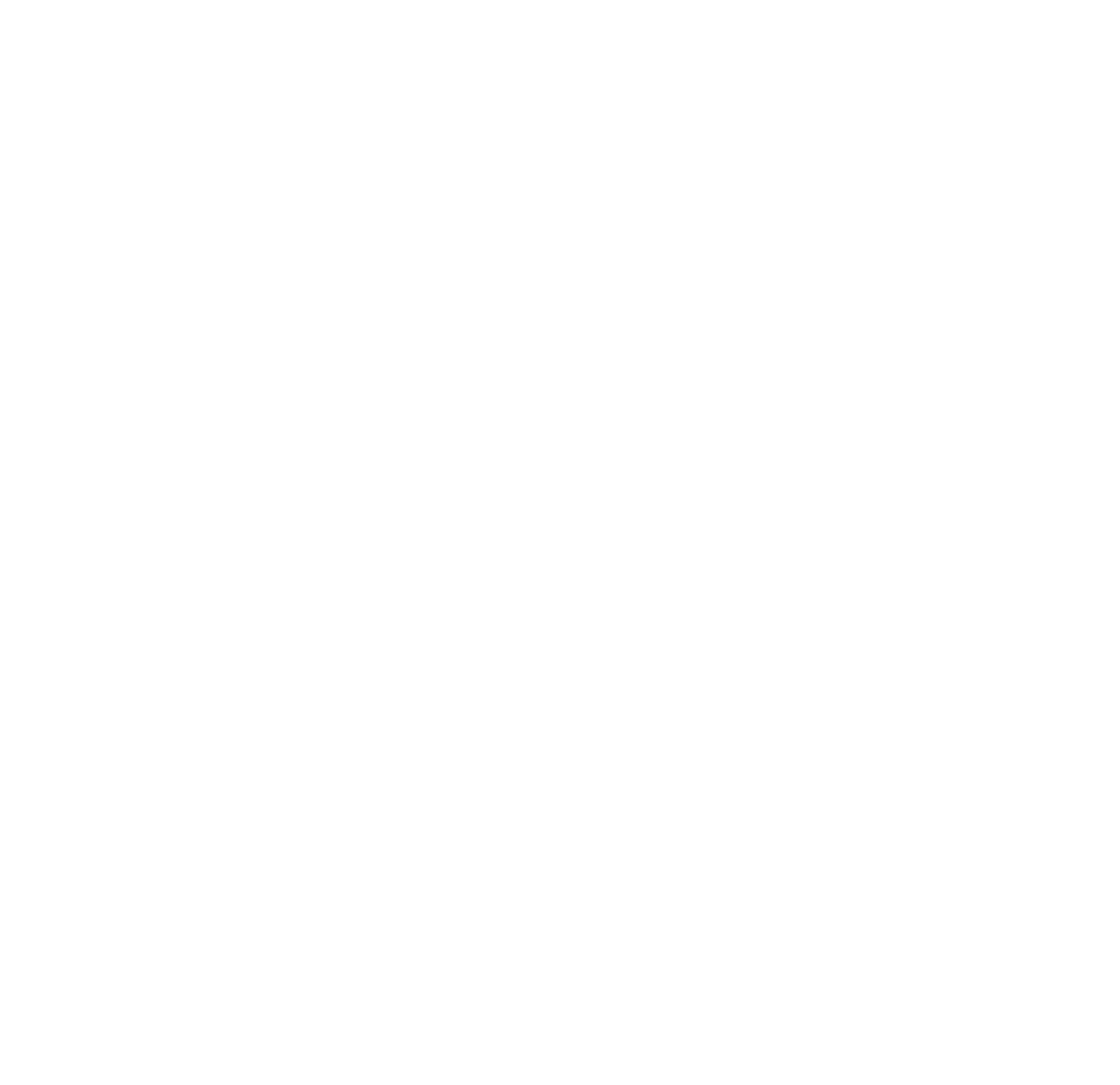

